\title{
Knowledge Management in Vocational Training - A Case Study of the EU Project RELOAD
}

\author{
doi:10.3991/ijac.v3i4.1383
}

\author{
F. Welter ${ }^{1}$, T. Thiele ${ }^{1}$, O. Pfeiffer ${ }^{2}$, A. Richert ${ }^{1}$ and S. Jeschke ${ }^{1}$ \\ ${ }^{1}$ RWTH Aachen University/Center for Learning and Knowledge Management and \\ Institute of Information Management in Mechanical Engineering, Aachen, Germany \\ 2 Technische Universität Berlin (TU Berlin)/Center for Multimedia Education and \\ Department of Mathematics and Natural Sciences, Berlin, Germany
}

\begin{abstract}
The ne ed of dive rse busine sses to qualify the ir employees by means of vocat ional training is in most cases connected with $h$ igh efforts du e to exp ensive face-to-fa ce courses an d do wntimes of $t$ he emp loyees. Although, th $e$ emergence of I T-based kn owledge ma nagement an d e-learning tools le $d$ to a br oader $r$ ange of e ducation possibilities during the last years, the fact rema ined that too many ap proaches were $n$ ot user- or learn er-centred. Besides, a lot of voc ational training approaches did not include modern didactic concepts which foster a self-directed way of learning. Hence a s tronger consideration of the interplay of the aspects "human, organisation and technology" - the so called HOT-Ap proach - can h elp to overc ome th is ch allenge. Referring to th is, a s uccessful case study is presented with the EU P roject RELOAD in th is paper. The focus of the $p$ roject RELOAD is $s$ et on emp loyees of the Do-I $t$ Yourself (DIY) industry in which employees as w ell as consultants p lay a d ecisive rol e b ecause th ey communicate $d i-$ rectly with end customers during sales and consulting talks. Due to the fact that a lot of employ ees and $c$ onsultants in this sector are $u$ ntrained, low $q$ ualified workers, or even workers from o ther sectors, a tailor-made vocational training is necessary. With regard $t o$ this, RELOAD tries to address employees and customers at the same time by offering a knowledge platform as a s emantic-based solution. This platform contains e-learning modules e nabling the use rs to actualise th eir knowledge mu ch more effic ient, fas ter and self-directed than by the us e of conventional vocational training appr oaches. $M$ oreover, this kind o f se If-directed learning $c$ an e asily be inte grated into dy namic daily work processes and at the same time it is more cost-efficient. As a consequence of th e p roject $r$ esults, variou $s$ DI $Y$ retailers show in terest to $u$ se an d furth er d evelop th e RELOAD knowledge plat form. With re gard to this, new ideas and needs for research are elaborated by the project consortium to set up a following-up project in future.
\end{abstract}

Index Terms-Knowledge Management, e-learning, Do-ItYourself indus try, Micr otraining, Se mantic te chnologies, Knowledge Platform.

\section{INTRODUCTION}

Knowledge in terms of an economic factor gains globally an increasing importance. Hence the acceleration of the information- and knowledge-growth as well as change processes in the society require a new understanding of learning and the willingness for a continuous personal education. Furthermore, the growing demands of the information- and knowledge-society require that each indi- vidual needs to focus more on self-learning. This means that individuals also have to adapt qualifications and skills independently to the needs of a respective working environment to ensure employability through self responsibility. In a strategic study conducted by the German Federal Ministry for Research and Education in the year 2003, various trends were identified with regard to the education requirements of the future [1]. One of these future trends depicts the fact that (lifelong) relearning will become common [2]. Referring to the latter, relearning can be defined as the ability of an individual or a single employee to acquire new knowledge in an independent and selfdetermined manner with regard to the respective professional background. Hence, relearning is necessary to update knowledge continually and to be able to cope with developments which are relevant for a profession, e. g. the introduction of new technologies or working processes. Additionally, in case of changing framework conditions and working processes it is also important to forget about already acquired professionally-oriented knowledge.

\section{A. New Media as an Approach to New Requirements}

To meet the increasing demands of the contemporary business world, an increasing learning competence is essential. This means that the individual needs to have the ability to begin a learning process auto didactically and to continue and finish this process successfully. An approach to support these learning processes provides the integration of new media in education. Today the internet constitutes the first source of new information and new knowledge, even in the field of vocational training [3]. According to this, web-based e-learning applications aiming to transfer knowledge can contribute essentially to this development [4]. Nevertheless, it is crucial that the human (respectively the learning individual) as well as didactic concepts may not lag behind the implemented tools of an IT-based knowledge management or e-learning. This means that the broad range of possibilities, which come up through global networking, a fast transfer as well as a location-independent availability of information and knowledge, has to be used in a sensible way. In doing so IT-based knowledge management and elearning applications can be implemented in a tailor-made manner to help learning individuals to meet the demands of a knowledge-based society.

With regard to the latter a general approach should follow the so called HOT-Approach [5]: 
- First of all it is necessary to identify and to promote the users' abilities, basing upon the respective mental model and the needs of the users (Human).

- Secondly the organisational framework has to be optimised (e. g. learning on the job, learning by doing, learning with formalised education) (Organisation).

- In the third step an inquiry has to be accomplished in how far possibilities of e-learning approaches (and attached technologies) can support the process of relearning (Technology).

Pertinent research results in knowledge management have already proved that just a holistic approach has a sustainable impact and that it is promising to combine it with blended learning approaches [6].

\section{B. Knowledge Management in Vocational Training: Former and Contemporary Developments}

Enterprises have to face the challenge of acquiring new knowledge continuously, especially with regard to restricted resources of small and medium sized enterprises (SME). In how far the actualisation of employees' knowledge can be managed thus constitutes still an unsolved question for various SME. Hence, methods are required which train employees as effective, fast and cheap as possible. At the same time these methods have to be able to cope with a growing knowledge production. Because of that, a huge number of enterprises followed the trend to implement IT-based knowledge management tools and elearning applications as an answer to these challenges during the 1990s. However, it became apparent that employees in these enterprises did not learn self-directed just because of introduced e-learning applications. One can state that too often it was not the learner who was in the centre of such applications but the technical realisation of the learning contents. Parallel to that the fast technical progress was not accompanied fast enough by the development of adequate pedagogical concepts. Moreover, the majority of e-learning applications are restricted in terms of providing factual knowledge. Although this form of knowledge can be reproduced correctly by methods of knowledge management and e-learning platforms, the utilisation of this knowledge in practice cannot be described as a logical consequence of the reproduction [7]. Because of this, a rethinking took place during the last years leading to a shift from technical centred knowledge management and e-learning applications to human or learner centred approaches (including methods and didactic).

With regard to this, especially the integration of elearning into daily work and self-organized forms of learning becomes more important than classical forms of education. Due to continuously increasing costs and more dynamic working processes it is more difficult to integrate the latter forms into the daily working environment. These new forms of self-directed learning through the help of new media correspond with the theoretical approach of the constructivism. This approach describes learning as an active construction process which is strongly embedded into a social context and which is characterised as a situational process [8]. Furthermore, the constructivist consideration of learning processes focuses on self-organisation. As a consequence of this consideration, learning processes can just be stimulated externally (perturbation) but they cannot be transferred into direct knowledge [9]. Against this backdrop the basic intention of all supporting measures changes: The measures do not aim at transferring knowledge from one person to another but they provide knowledge resources and learning support in terms of enabling learning [10].

\section{Semantic Technologies as a Solution}

Considering the former described development, the key to an effective utilisation of knowledge management and e-learning approaches in vocational training constitutes a sensible networking of the stored information to be able to exploit new knowledge. This means that information only depicts a value for humans when they are able to realise the impact of the respective information in a concrete situation. At this point semantic technologies for knowledge management come into play, because semantics allow the decisive step from information to knowledge [11]. Referring to this it has to be stated that the latter is always embedded into a specific context of action. Thus knowledge is developed throughout a specific situational pattern of information and enables humans to act in a sensible manner (cf. Figure 1).

The crucial value of semantic knowledge management applications in the area of vocational training thus can be described with an augmentation of the quality of information. This augmentation happens through demand-oriented networking of information in the context of organisationspecific targets and concrete processes. Due to this kind of networking the employee or learner receives the required contextual information - independent from location and time - which can enable the development of new knowledge [13]. Nevertheless, enterprises integrate social software and semantic knowledge management applications only hesitantly in their business environment, maybe because of the fact that business applications have other requirements than applications for private users. Furthermore, the reason for a still limited diffusion of semantic knowledge management solutions can be explained in particular with the costs and efforts of introducing such systems. Hence it is necessary that the effort of introducing semantic systems has to be compared directly with the benefits originating in an optimised information quality which e. g. cannot be provided by simple search engines. The benefit of the latter just focuses on the fact of saving time while searching for information. In comparison to that semantics make information easier accessible within work-specific learning processes and because of that they contribute directly to value added.

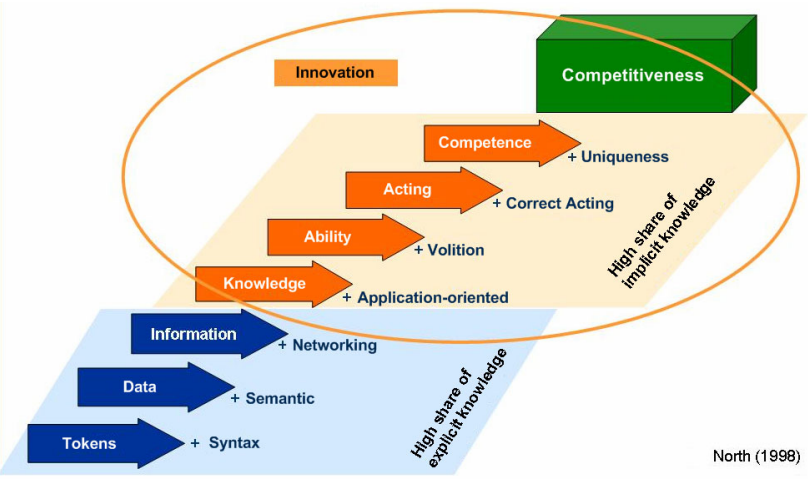

Figure 1. Steps of Knowledge Development (extended after "Wissenstreppe”, North 1998) [12] 


\section{Microtrainings as a Didactic Solution}

Concerning the human perspective of the HOTApproach the emergence of new self-directed learning concepts can be stated during the last years, which are also promising for various businesses in combination with semantic technologies. With the approach of so called Microtrainings (which aim to train learners in a short period of time) such a promising concept shall be described in the following section.

A typical Microtraining unit is characterised by a duration of approximately 15 to 30 minutes. The relatively short time is important with regard to the target group e. g. consisting of people who work in fixed shifts or on location such as production staff, installers, builders, sales people etc., from which at least some would lose interest or would be overstrained by longer learning units. Thus, each unit begins with a short activation of the participants by introducing them into the topic and by pointing out the target of the unit. Furthermore, a short (multimedia) demonstration or exercise is given to introduce every participant into the topic. E. g. this can be done with a video and a short exercise about technical details of a tool or details of a service process. These first sections are followed by a phase of discussion and feedback in which questions to different items, products or processes are posed to stimulate the group of learners to actively share their (tacit) knowledge. Especially with help of the questions it becomes possible to control if the input was understandable for all participants. In the final phase of a Microtraining unit, a short summary of the formerly learned content is provided, underlining the main learning achievements for the users and giving a short preview of further units in order to stimulate interest in visiting following learning units [14].

Hence it seems to be obvious that the basic idea of Microtrainings - which aims to train people within several minutes - is predestined to combine it with an adequate semantic IT-environment offering the opportunity of a self-directed learning e. g. by providing training units on a web-based platform. In how far such an idea can be put into practice shall be elucidated with the following case study of the EU project RELOAD.

\section{THE CASE STUDY: A SEMANTIC BASED LEARNING AND KNOWLEDGE PLATFORM FOR THE DIY-INDUSTRY}

In the EU founded project RELOAD a multinational consortium of Universities, DIY retailers and branch experts developed a semantic based learning and knowledge platform in order to enhance the vocational training of employees in the DIY industry. This target audience is mainly untrained and less qualified regarding their primary duty as sales assistants by counselling interviews with end customers. Various learning platforms have been developed directly by DIY retailers and they were integrated in already existing vocational workshops, but so far there has been no breakthrough in establishing an elearning standard in this branch. As one step to enable this standard, the RELOAD platform was designed under the above-named Human-Organisation-Technology (HOT)Approach and the principles of the constructivist learning theory.

\section{A. Didactical approach (Human)}

The primary aspect of the constructivist learning theory is the self-reliance and self-responsibility of the learner. Comprehension is constructed through reasonable interpretation of information. As an active process interpretation of information is based on the learners' previous knowledge. Since the RELOAD learning platform is designed to cope with the needs of experts and apprentices, the learning process has the requirement to be individual. In order to support the above mentioned interpretation as an active process, the platform presents an interactive environment to the learner to enable the construction of an individual comprehension.

In addition to that, following the constructivist learning theory, the construction of individual knowledge and comprehension requires the exchange between the learners. The enhancement of this exchange is a key element to create a better learning effort. By implementing a method to ensure communication and exchange between the learners the vocational training gets more authentic, meaning that the learning lesson should correspond to the cognitive context and requirements of the learners' working environment [15]. To embed information into a context is another strategy to ensure a better result in the procurement of knowledge. The learner assimilates the information in the context it is presented and therefore gets a deeper understanding of the presented elements. The content of the RELOAD platform has to fulfil the needs and requests of the learners. Therefore it has not only to answer daily questions with which an employee in the DIY branch has to cope with, but also to distribute practice oriented information, which enables the employee not only to sell an item, but to guide the customers in their projects.

One of the main disadvantages of a classical vocational workshop is the cost for a workshop. The employer does not only have to pay the workshop, but also has to bridge the downtime of the employees. In the learning environment of the RELOAD platform this problem was addressed by using a learning-on-the-job model.

The learning scenarios of the learning-on-the-job platform differ from standard applications. For the DIY branch it is typical that only a few employees use personal

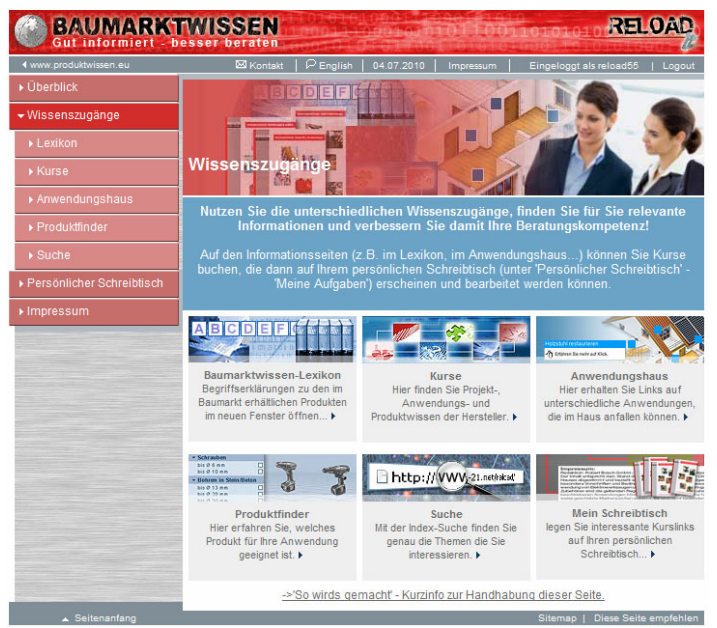

Figure 2. The start-up screen of the RELOAD learning platform, listing various entries for the learning scenarios 
computers in their daily working routine and therefore they have no easy access to the learning platform. As a result most employees are not experienced in the use of personal computers and must leave the sales room to use the platform in a computer room. Although this might be a disadvantage, a separate computer room creates a better environment for a concentrated and undisturbed learning process. Hence, to support the individual learning in a typical learning scenario the platform offers different approaches for the learner to entry a lesson. Selected scenarios shall be described by the examples:

- "Guided Tours"

- "Product Finder"

- and “Application House” (cf. Figure 3).

The "Guided Tours" compensate the lack of tutorial support during a lesson. Especially designed for apprentices this tours offer guidance in typical customer problems and projects. Advanced learners may start directly into a lesson and may skip certain steps.

Beside the "Guided Tours", learners can enter the platform through a lexicon. Rather the access for advanced learners, the lexicon lists all topics in alphabetical order. Especially designed to distribute knowledge in the field of product characteristics the "Product Finder" specifies power tools dependant on different criteria. These criteria are based on typical customer claims.

The entry "Application House" is a project based approach. In the range of characteristic activities around preliminary building works, house development and renovation the user can virtually move to different rooms and areas in a house and select learning lessons in the context of the room. For example, if the user hits the parquet lined living room, one of the units offered in the renovation modus is "floor polishing".

The "Anchored Instruction" principle focuses on the anchoring of content by motivating and meaningful episodes. In doing, so previous knowledge is activated aiming at an active learning process. Incorporating know-how and operating experience, interest and intrinsic motivation advances as well as the development of inactive knowledge is reduced. Although demanding a multimedia based learning platform and therefore raising the deployment complexity, this use of media creates an environment of self-directed learning towards new abilities and skills. Supplemental to the "Anchored Instruction" the "Cognitive Apprenticeship" is implemented to ensure the transfer of practice oriented intercession principles to the handling of complex problems. As the didactical basis for the structure of a learning lesson these two approaches form the framework for the concrete elaboration of Microtrainings in RELOAD.

\section{B. Knowledge Model (Organisation)}

Due to the fact that RELOAD constitutes a project within the "Lifelong Learning Programme 2007-2013" (Leonardo da Vinci) of the European Union, the intention of the project was to transfer innovations into practice. Thus, an adequate organisational framework was considered which based on the learning on the job concept. Concerning the latter the consortium agreed in the decision to realise the concept by the implementation of Microtrainings.

As mentioned in chapter I. D. Microtrainings are short, group based learning lessons following the general struc-

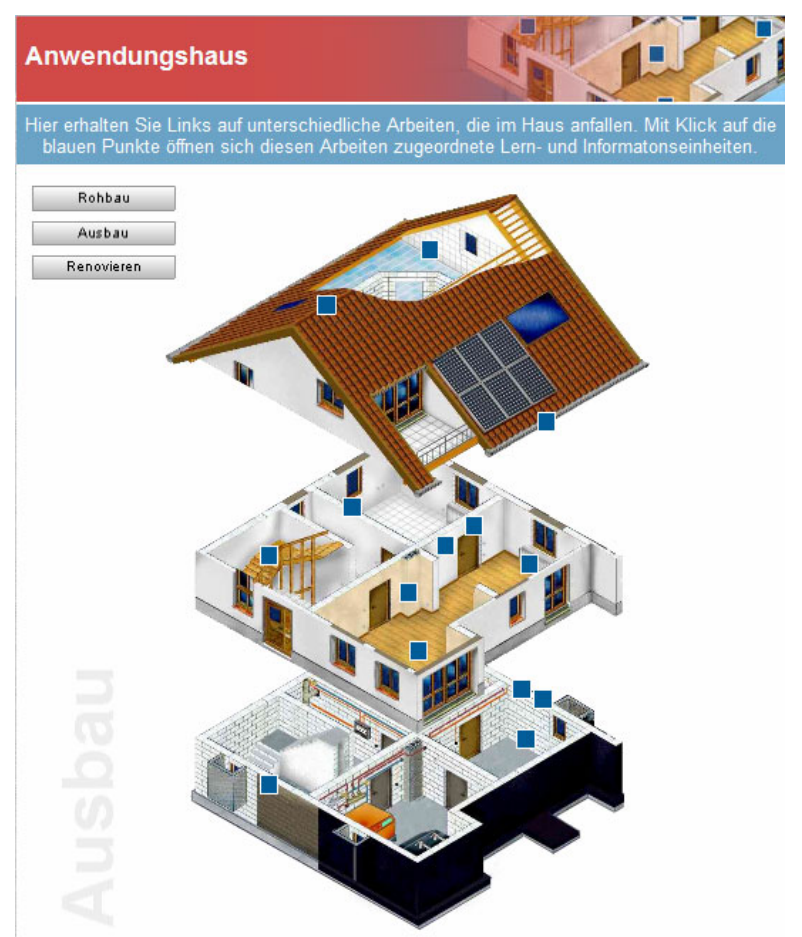

Figure 3. The RELOAD "Application House" (Blue boxes indicate learning lessons - here in the field of renovation).

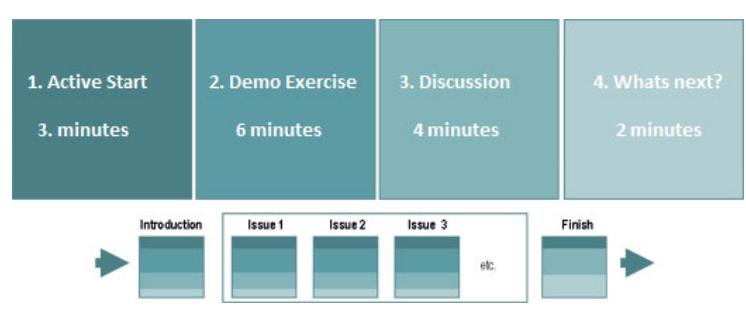

Figure 4. General structure of a Microtraining unit [14]

ture in Figure 4. Due to the short duration the learner focuses on the given task and the downtime of the personal is minimal.

Regarding the requirements of the didactical concept of

- an interactive environment to construct individual comprehension,

- exchange between the learners,

- learning on the job

- and reduced costs

Microtrainings are a suitable organisational form for the learning sessions. For the needs of RELOAD the already short duration of 15 to 30 minutes is decreased down to 5 to 15 minutes due to a target audience, which is not familiar with learning. Daily problems resulting from customer counselling serve as a narrative anchor for the learner and therefore as active start for the Microtraining. The demo exercise of the session can easily be realised by a multimedia platform. Manufacturers of the DIY industry integrated their instruction documentation, formerly used in vocational workshops, into the platform resulting in higher cost effectiveness for the manufacturers and the retailers. Considering the multimedia character of the RELOAD platform pictures, video-simulations and documents can be stored as a demo exercise. Subsequent to the exercise the leaner is invited to practice the acquired knowledge and therefore internalise the presented infor- 
mation. Supported by a dialogical structure of the platform the user gets more and more used to self-directed learning. The Microtrainings are divided into sections of different content and difficulty. Thus it is assured that learners with different vocational background can choose topics according to their level of knowledge. As another side-effect a large flexibility of knowledge acquisition is offered. As a third step of the Microtraining the following discussion is enabled through a feedback. The users are encouraged to comment the content as well as the offered media. The operator company is thereby in the position to identify possible weaknesses in the contents of the RELOAD platform. The "What's next?" step of the lesson is an integral part to embed the content into a greater coherence and thus to realise the authenticity and practice relevance of the learning unit.

The content of a Microtraining unit meets the requirements of a counselling interview. The first step of a lesson imparts product knowledge. After a short test to ensure the sustainability of the information a chapter on "how to utilise the product" follows. The last part of the lesson trains selling knowledge and is based on the previous fundamentals. This structure assures that the user not only obtains all necessary information to support the projects of potential customers, but also learns how to organise a counselling interview.

Following the above mentioned didactical model embedding information into a context is a key strategy to create authenticity and sustainability of knowledge. In RELOAD most lessons are connected through a Semantic Net. By intelligent and non-linear connections it is ensured that further links are offered, which lead the user to new topics and encourage the construction of new mental associations between different areas in the DIY branch. For example, if a user looks up the lesson "How to tile a Bathroom?", an additional reference leads to the installation of a basin. Thus the user learns to think of complete projects and therefore gains the ability to provide advice not mentioned by the customer. Since the Semantic Net as organisational form of the knowledge supports the ideas of the didactical concept, the technical realisation is the next step in the HOT approach.

\section{The Realisation of RELOAD (Technology)}

Concerning the technical realisation of RELOAD a web-based approach is implemented to enable a broad accessibility for various users. Hence the web-based approach allows a time- and space-independent access and offers parallel to that a design in the style of common websites. Because of this, the users of the knowledge platform are trained in the utilisation of new media, too.

The basic concept of the RELOAD platform is a relational database. Not only this technology ensures great flexibility and an easy-to-use administration, but it is also a practicable basement for the implementation of the Semantic Net and as an authentic learning environment. Mainly based on linked spreadsheets the contained data can be easily connected and combined. By the rules of relational algebra a mathematical description was developed in order to define distinct rules and operators [16]. By using these features the database becomes flexible and can be (re-)organised according to the wishes of the user. As a key element for the successful implementation of the Microtrainings this individual storage and arrangement capability meets exactly the requirements of the construc- tivist learning theory, mentioned in chapter I. A. Through its individuality the system creates a non-static learning situation, which can offer different approaches to the stored contents. Thus the user can choose the right way for him to learn. Another advantage, this system offers, lies in the customisation capability of the database. As the assortment of goods varies, each local supervisor can readjust the contents to fit the distinct alignment of his products.

As mentioned in previous chapters the Semantic Net logically and didactical reasonably connects the entries of the platform. At the end of each learning session a so called "link-box" offers associative related topics with the aim to encourage the further learning process. The content of the "link-box" is automatically generated by meta data, which is implemented into the relational database. This meta data is based on classes and objects. Classes can be seen as categories for the products and therefore structure the content in the above mentioned topics. The objects are specifications of these categories and real entities, in the case of RELOAD typical products of the DIY branch. Both classes and objects form key attributes of the meta data used to form the relations of the Semantic Net.

Based on MY-SQL and ZOPE objects the Semantic Net implements a personal learning path through the content of the platform. Tracked on a "personal learning desk" this technology enables the retracing of the learning process and therefore supports the idea of a self-determined learning process by visualising already started and completed training units. As the Semantic Nets connects all entries of the RELOAD platform different types of connections have to be created because of the various approaches noted above (see Figure 5).

As a primary technology to incorporate new Microtrainings into the RELOAD platform, a template has been developed. Based on Microsoft's Power Point this interface is available to most content creators and demands little practising time, but also supports the multimedia approach of the platform.

\section{RESUlTS \& CONCLUDING REMARKS}

With regard to the introduction of new learning approaches in vocational training huge efforts were undertaken by enterprises as well as universities in the last decades. Still one of the main challenges can be described with providing a low cost vocational training approach which motivates employees to use it in a self-directed

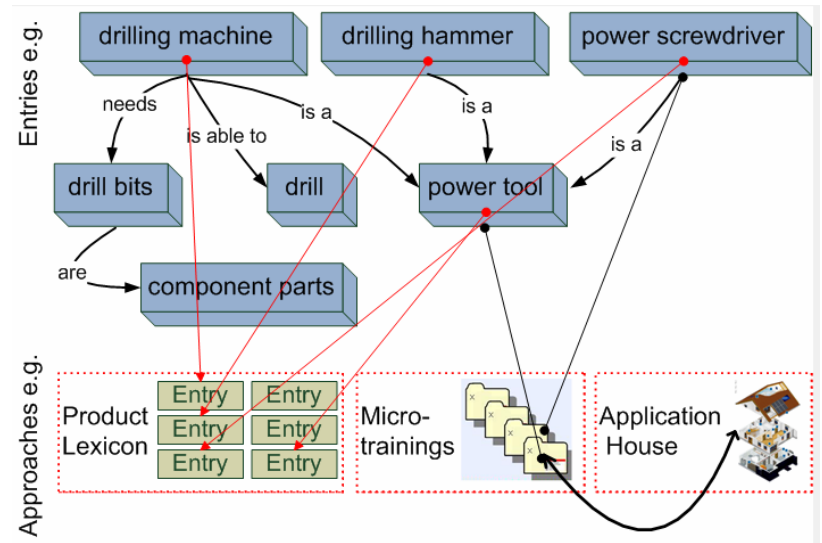

Figure 5. Extract of the Semantic Net used in the RELOAD platform 
way. Thus, contemporary developments in knowledge management and e-learning focus more on a human centred design than in the last years in which technology centred designs prevailed. Since a closer integration of new didactical concepts with adequate knowledge management and e-learning tools takes place nowadays, advantages become obvious e. g. through the stimulation of a selfdirected learning among various groups of employees.

Furthermore, the introduced case study of the EUfunded project RELOAD highlighted a successful advance in the field of vocational training. Because of the fact that the so called HOT-Approach (Human, Organisation and Technology) was considered during the entire project runtime, requirements on different levels were analysed to create a holistic vocational training that can be applied in the DIY-Industry. Hence, the main innovations of RELOAD can be characterised with the integration of Microtrainings as a special didactical form and the use of semantic technologies as a non linear form of knowledge management. Due to the fact that many employees and consultants in DIY stores are untrained, low qualified or even workers from outside the sector, the integration of Microtrainings and semantic technologies in RELOAD was successful as it is revealed in project internal test runs in the years 2008 and 2009.

Through the results of the test phases in the participating DIY stores it became obvious that the target group handled the provided applications on the RELOAD knowledge platform in a satisfying manner. Nevertheless, general deficits of the employees in the DIY branch became obvious, too, concerning the general use of personal computers and the familiarity with internet applications. The latter could be underlined by a couple of qualitative user interviews which have been conducted after the test phases by partners of the RELOAD consortium. As a consequence, providing personal trainers (in combination with an individual training schedule) could be another possibility for those employees who are inexperienced in using computer applications. In general, the platform received a positive feedback with regard to the usability of its Microtraining units. Referring to this, one can stress that the use of the Microtraining units seems to be more effective for the employees during their working time (learning on the job) in comparison to complete learning units at home.

Concerning the RELOAD business model various DIY retailers showed interest in a continued use of the knowledge platform in order to reduce the costs of classical vocational courses. With regard to this the commercial supply of e-learning units can be seen as a chance for the RELOAD knowledge platform, although a continuous further development of contents and learning units is necessary to meet the demands of a broad range of retailers.

\section{FUTURE PROSPECTS}

A next step in future could comprise a certification of the informal learning concept integrated in the RELOAD knowledge platform in order to create a standardised form of vocational training by the use of new media. With regard to this, a further integration of suppliers from the DIY-industry is desirable in future and should be attempted in follow-up projects. Especially a broader range of partners from different European countries could be interesting to develop multilingual learning units which e. g. could provide a standard for different actors of the DIYindustry within the European Union.

Besides, a more standardised concept of the RELOAD knowledge platform could offer in particular small and medium sized enterprises (SME) the opportunity to market their products as well as to edit product information easily into standardised e-learning units. Moreover, the production costs for training materials can be estimated as relatively cheap in comparison to the costs for training sessions which are just performed face-to-face in classrooms. One can underline that through the gained cost advantages for SME a general strengthening of this kind of enterprises is possible. Thus RELOAD caters the overall long-term strategy of the European Union to foster SME in a sustainable way.

On the technical side the RELOAD platform revealed great flexibility in order to respond to the needs of the learners. The extension of this ability can be seen in the development of a didactical tool box. This would allow different DIY retailers to customise the platform regarding their individual requirements concerning distinct learning approaches (e. g. Blended Learning, e-learning et cetera). Especially the application of the RELOAD platform in a Blended Learning environment would benefit on the implementation of Web 2.0 technologies. Although a feedback function has already been integrated, user generated content would increase the information flow and would be a logical advancement in consideration of the HOT approach.

Through the successful realisation of the RELOAD project the elaboration of new project ideas - which are basing on the key outcomes of RELOAD as well as on further need for research - is impelled by the entire consortium. Thus, e. g. a further need of research can be described with the optimisation of the web interface design for different groups of users and employees. With regard to this, the efforts to continue the work on a sustainable knowledge management and e-learning approach in vocational training will be intensified in future.

\section{REFERENCES}

[1] Bundesministerium für Bildung und Forschung (2010, July 7) Ed. "Deutsche Weiterbildungsanbieter auf internationalen Märkten. Daten - Fallstudien - Perspektiven“ [Online]. Available: http://www.bmbf.de/pub/deutsche_weiterbildungsanbieter.pdf

[2] P. Dassen-Housen, "Responding to the global political-economical challenge: The learning society exemplified by the working environment," Aachener Reihe Mensch und Technik, Band 32, Wissenschaftsverlag Mainz in Aachen, Aachen, 2000.

[3] H. Zinnen (2010, October 21), "Wissensmanagement in der Berufsbildungspraxis" [Online]. Available: http://www.bibb.de/ dokumente/pdf/a23_foko3_wissensmanagement_PeineNovember_2005.pdf

[4] H. Maurer, "E-Learning muss als Teil von Wissensmanagement gesehen werden," in LOG, Heft 6, 2000, pp. 24-27.

[5] S. Frank and A. Streit, "Implementing Service Orientation in Production Enterprises,” in Human-Centred System Design. First: People, Second: Organisation, Third: Technology, D. Brandt, Ed. Aachener Reihe Mensch und Technik, Band 42, Aachen: Wissenschaftsverlag Mainz, 2003, pp. 54-62.

[6] K. Henning and G. Schöler, Eds. "Knowledge is orange. IndustryFocused Applications of Knowledge Management across Germany,” Aachen: Wissenschaftsverlag Mainz, 2004.

[7] K. Schnurer and H. Mandl, "Wissensmanagement und Lernen," in: Psychologie des Wissensmanagements, G. Reinmann and H. Mandl, Eds. Göttingen, 2004. 
[8] G. Reinmann-Rothmeier and H. Mandl, "Lernen neu denken: Kompetenzen für die Wissensgesellschaft und deren Förderung," in: Schulverwaltung, 3, 1997, pp. 74-76.

[9] R. Arnold and H. Siebert, "Konstruktivistische Erwachsenenbildung,” Hohengehren, 2003.

[10] R. Arnold and C. Gómez-Tutor, "Grundlinien einer Ermöglichungsdidaktik. Bildung ermöglichen - Vielfalt gestalten,” Augsburg, 2007.

[11] H. Beier, "Vom Wort zum Wissen, Semantische Netze als Mittel gegen die Informationsflut,” in: Information Wissenschaft \& Praxis, Deutsche Gesellschaft für Information e.V., Ed. Ausgabe 3, 2004.

[12] K. North, „Wissensorientierte Unternehmensführung. Wertschöpfung durch Wissen,“ Gabler: Wiesbaden, 1998.

[13] H. Beier (2007, October 27), "Semantisches Wissensmanagement = Qualitätsmanagement für Informationen” [Online]. Available: http://www.community-of-knowledge.de/pdf/Beier_Semantik.pdf

[14] Microtraining - What can you learn in 15 minutes? (2010, July 4) Homepage of the EU Project Microtraining. [Online]. Available: http://www.zlw-ima.rwth-aachen.de/forschung/projekte/microtrai ning2/htm/method.html

[15] G. Mietzel, "Pädagogische Psychologie des Lernens und Lehrens,” Hogrefe: Göttingen, 2007, pp. 46-50.

[16] E. F. Codd, "A Relational Model of Data for Large Shared Data Banks," in: Communications of the ACM, ACM Press, New York, $13^{\text {th }}$ June 1970 , pp. $377-387$.

\section{AUTHORS}

F. Welter M.A. is researcher at the Center for Learning and Knowledge Management and Institute of Information Management in Mechanical Engineering, RWTH Aachen University, Aachen, Germany, Dennewartstrasse 27, 52068 Aachen (e-mail: welter@zlw-ima.rwth-aachen.de).
T. Thiele (cand.-ing.) is student assistant at the Center for Learning and Knowledge Management and Institute of Information Management in Mechanical Engineering, RWTH Aachen University, Aachen, Germany, Dennewartstrasse 27, 52068 Aachen (e-mail: thiele@zlwima.rwth-aachen.de).

Dipl. Math. Olivier Pfeiffer is researcher at the Center for Multimedia in Education and Research at the Department of Mathematics and Natural Sciences, Technische Universität (TU) Berlin, Berlin, Germany, Strasse des 17. Juni 136, 10623 Berlin (e-mail: pfeiffer@math.tuberlin.de).

Dr. phil. Anj a Richert is head of the section Knowledge Management at the Center for Learning and Knowledge Management and Institute of Information Management in Mechanical Engineering, RWTH Aachen University, Aachen, Germany, Dennewartstrasse 27, 52068 Aachen (e-mail: richert@zlw-ima.rwth-aachen.de).

Professor Dr. rer. nat. Sabi na Jeschke is head of the Center for Learning and Knowledge Management and Institute of Information Management in Mechanical Engineering, RWTH Aachen University, Aachen, Germany, Dennewartstrasse 27, 52068 Aachen (e-mail: sabina.jeschke@zlw-ima.rwth-aachen.de).

This work was financially supported by the European Union in the "Lifelong Learning Programme 2007-2013” (Leonardo da Vinci) - Transfer of Innovation.

Submitted, July, $12^{\text {th }}, 2010$. Published as resubmitted by the authors on October, $17^{\text {th }}, 2010$. 